\title{
Effect of gluconate salt on mechanical and structural properties of heat-induced myosin gel
}

\author{
Atsushi OOI ${ }^{1}$, Yoshie SAKURAI ${ }^{1}$, Yohjiro TAMURA ${ }^{2}$, Fumiaki YANO ${ }^{1}$, Tsuyoshi OKAGAKI ${ }^{1}$ and Jun SHIRAI ${ }^{3}$ \\ 'Faculty of Bioresources, Mie University, Tsu 514-8507, Japan (ooi@bio.mie-u.ac.jp) ${ }^{2}$ Suzuka College of \\ Technology, Suzuka 510-0294, Japan ${ }^{3}$ Fujisawa Pharmaceutical Co., Ltd, Nipponbashi-Tokyo 103-0012, Japan
}

KEY WORDS: myosin gel, gluconate, breaking strength, specific volume, adiabatic
compressibility

\section{INTRODUCTION}

Gluconate salt is a potential food additive whose chemical structure is analogous to sorbitol. Recently, Takeshita et al. ${ }^{1)}$ reported that sodium gluconate not only protected myofibrillar protein against thermal inactivation but also solubilized it as a salt. Since these properties are closely related to the ability of gel forming of flesh paste, gluconate salt makes possible to improve consistency of minced fish product, e.g. kamaboko ${ }^{2)}$. In this work, we elucidated the effect of gluconate salt for thermal gelation of fish myosin, which is major component of salt soluble proteins governing elasticity of kamaboko. The mechanical and structural properties of heat-induced myosin gel prepared with sodium- or potassiumgluconate were studied. Furthermore, in order to obtain some information about molecular structure of myosin in a solution of gluconate salt, we studied partial specific volume and adiabatic compressibilty of myosin.

\section{MATERIALS AND METHODS}

Myosin was extracted from red sea bream ordinary muscle and purified according to the method of Reinach et al. ${ }^{3}$. At the final stage of purification each myosin was dissolved in a solution containing of $0.6 \mathrm{M}$ of various salts $(\mathrm{KCl}, \mathrm{NaCl}, \mathrm{K}$-gluconate, $\mathrm{Na}$ gluconate) and stored on ice. Stocked myosin was used within 3days after purification. Protein concentrations were determined by biuret method using bovine serum albumin as the standard. Stocked myosin was diluted to appropriate protein concentration with a buffer solution (pH6.5) of $20 \mathrm{mM}$ potassium phosphate, $1 \mathrm{mM}$ EDTA, $1 \mathrm{mM} 2-$ mercaptoethanol and $0.6 \mathrm{M}$ various salts to make myosin gel at appropriate protein concentration. Thermal gelation of myosin was performed in the
$1.5 \mathrm{ml}$ cuvette whose temperature was precisely controlled by thermobath. Mechanical strength of the gel was tested with Rheoner RE-3305 (Yamaden Co.) using a cylindrical plunger $(\phi=5.0 \mathrm{~mm})$.

Specimens for scanning electron microscopic observation were prepared according to the method of Yasui et al. ${ }^{4)}$ with slight modifications. Before the critical point drying, ethanol used for dehydration was replaced by isopentyl acetate. The dried specimens were coated with platinum palladium and observed with Hitachi JSM-T200 at an accelerating voltage of $10 \mathrm{kV}$.

Specific volume of myosin was determined from the density of myosin solution measured with a precision density meter, DMA-02C (Anton Paar, Gratz, Austria). Adiabatic compressibility was obtained from the velocity of sound in the myosin solution. The measurement of the sound velocity of a solution was performed by a 'sing-around pulse method' ${ }^{5)}$.

\section{RESULTS}

Fig.1 shows the typical patterns of the force development in the puncture test of the heat-induced myosin gels. It is clear that the breaking strength of the myosin gel prepared with gluconate salt is extremely larger than that of the gel with potassium or sodium chloride. The averaged breaking strengths were about 7.7- and 4.0-fold enhanced in case of potassium and sodium salt, respectively. The enhancement of breaking strength is not only reinforced effect of the heat-induced myosin gel by gluconate salt. It is well known that long heating time in the processing of kamaboko causes a degradation of 'ashi' (elasticity of kamaboko). The mechanical strength of the myosin gel prepared with gluconate salt was very little affected by prolongation of heating 
time. Fig. 2 shows the scanning electron microscopic images of the myosin gels prepared with potassium salt. Fine network structure was observed in the gel prepared with potassium gluconate (Fig.2(B)) compared with that of the gel with potassium chloride (Fig.2(A)). The pore size of the network appears different about 2 fold or more. Similar results were obtained for the gels with sodium salt. The mechanical toughness of the gel with gluconate salt described above may be possibly due to the dense matrix of protein.

In order to understand the effect of gluconate salt on gelation of myosin, it is important to know what kind of influence is caused on a myosin molecule itself by gluconate salt. Therefore, we investigated specific volume of myosin in a solution of gluconate salt. We found that the apparent specific volumes of myosin in gluconate solution were small compared with that in chloride solution. The partial specific volumes obtained by extrapolation of them to zero protein concentratoion are $0.725(\mathrm{KCl}), 0.712(\mathrm{NaCl})$, 0.662 (K-gluconate) and $0.655 \mathrm{~cm}^{3} / \mathrm{g}$ (Na-gluconate), respectively. The partial adiabatic compressibility of myosin was calculated from both the sound velocity of myosin solution and the partial specific volume. The obtained values were $8.31 \mathrm{~cm}^{2} /$ dyn for myosin in $\mathrm{KCl}$ and $-8.27 \mathrm{~cm}^{2} /$ dyn for myosin in K-gluconate, respectively.

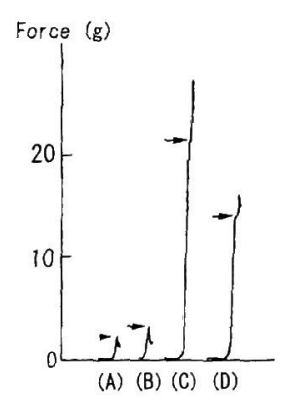

Fig.1 Force development of puncture test for the heat-induced myosin gels prepared with various salts.

The myosin gels $(15 \mathrm{mg} / \mathrm{ml}$ of myosin) prepared with $\mathrm{KCl}(\mathrm{A})$, with $\mathrm{NaCl}(\mathrm{B})$, with K-gluconate (C) and with Na-gluconate (D) by the heating for $15 \mathrm{~min}$. at $80^{\circ} \mathrm{C}$.

Each arrow indicates the breaking point of the gel.

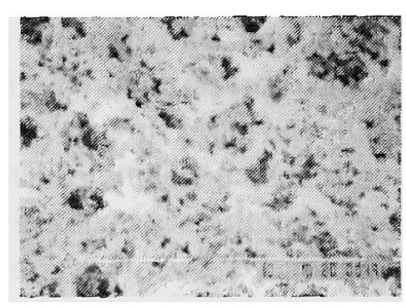

(A)

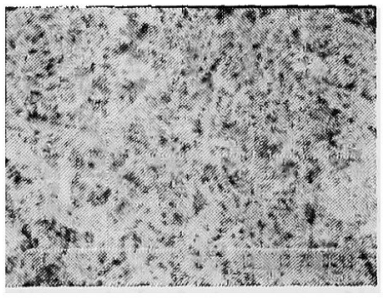

(B)
Fig.2 Scanning electron microscopic images of the heatinduced myosin gels prepared with $\mathrm{KCl}$ in (A) and $\mathrm{K}$ gluconate in (B). Magnifications; $\times 5,000$ Myosin concentration was $15 \mathrm{mg} / \mathrm{ml}$ in both (A) and (B). The white bar represents a length of $10 \mu \mathrm{m}$.

\section{DISCUSSION}

The partial specific volume of myosin determined in this work, $0.655-0.662 \mathrm{~cm}^{3} / \mathrm{g}$, are much smaller than those of other proteins previously reported ${ }^{6}$. There are two possible explanations for the small partial specific volume. The first is a decrease of the cavity of myosin upon immersion into gluconate solution. Since the cavity of protein is very important for its function, such a significant decrease of the cavity must cause inactivation of the protein. But this is not the case, because ATPase activity of myosin was still remained in gluconate solution (data not shown). Another possibility is an increase of hydration of myosin molecule by gluconate salt. The fact that the partial adiabatic compressibility of myosin in gluconate solution showed negative value strongly supports it. It seems reasonable that the increase of hydrated water stabilizes myosin and results in stiffening heat-induced myosin gel.

\section{ACNOWLEDGEMENT}

The authors are grateful to Dr. Satoshi Ogawa, Ultrastructure center in Mie University, for his technical supports in the scanning electron microscopic observations.

\section{REFERENCES}

1. Takeshita M, Ooizumi T, Akahane Y, Takenawa S. Effects of sodium glunonate on thermal denaturation and solubilization of carp myofibrils. Nippon Suisan Gakkaishi 1999;65:886-891.

2. Takeshita M, Ooizumi T, Akahane Y, Abe Y, Kitagami S, Murakami Y, Takenawa S. Effect of Na-gluconate on characteristics of two-step heated gel from walleye pollack surimi. Nippon Suisan Gakkaishi 2000;20:291-297.

3. Reinach F, Masaki T, Shafiq S, Obinata T, Fischman DA Isoforms of $\mathrm{C}$-protein in adult chicken skeletal muslce: detection with monoclonal antibodies. J.Cell Biol. 1982;95:78-84.

4. Yasui T, Ishioroshi M, Nakano H, Samejima K. Changes in shear modulus, ultrastructure and spin-spin relaxation times of water associated with heat-induced gelation of myosin. $J$. Food Sci. 1979;44:1201-1204.

5. Tamura Y, Suzuki N, Mihashi K. Adiabatic compressibility of myosin subfragment-1 and heavy meromyosin with or without nucleotide. Biophys. J. 1993;65:1899-1905.

6. Gekko K, Hasegawa Y. Compressibility-structure relationship of globular proteins. Biochemistry 1986;25:6563-6571. 